\title{
Support for New Career Academics: an integrated model for research intensive university business
}

\section{and management schools}

Dr Andy Adcroft (corresponding author)

Centre for Educational and Academic Development

University of Surrey

Guildford

Surrey

UK

GU21 2TQ

e-mail: $\quad$ a.adcroft@surrey.ac.uk

Tel: $\quad+44(0) 1483682007$

Dr David Taylor

Leeds University Business School

Maurice Keyworth Building

University of Leeds

Leeds

LS2 9JT

e-mail:

D.T.Taylor@lubs.leeds.ac.uk

\begin{abstract}
The aim of this paper is to examine the general and discipline specific support needed by academics new to the profession. The paper takes a social process approach to the examination of the experiences of new academics. The approach taken is, therefore, qualitative in nature and centres around a series of semistructured interviews carried out with new academics and senior managers in two research intensive business schools in the UK. The research suggests that there are four crucial dimensions to successful career support for new academics: managing expectations, career management, mentoring and professional development. Whilst it is important to offer good practice in each of these dimensions, the paper argues that it is the relationship between them which determines the quality of career support offered. The paper offers a number of original insights into this issue and contributes to both the literature on career support for new academics and to practice with a conceptual model which may have applicability across a number of different settings.
\end{abstract}




\section{Introduction}

Gappa et al (2005) suggest that 'the continued vitality of the academic profession is ... of concern to a very large number of people and institutions' (p.32) and central to that vitality is the recruitment and development of new career academics (NCAs). This paper takes a social process approach to the examination of the experiences of NCAs and develops a conceptual model which integrates a number of different elements related to career support for newcomers to academia. There are four key elements which must be addressed: the expectations of newcomers to academia, short and long term career management especially in balancing the demands arising from the complex relationship between teaching and research, the role of mentoring in the development of new academics, and professional development mechanisms especially those resulting from institutional requirements regarding postgraduate programmes in academic practice (PPAP). The paper is organised in a straightforward way. The next section provides some underpinning theory with a discussion of the nature of academic work and how this creates a number of tensions which NCAs must navigate their way through in the early stages of their careers. This is followed by a discussion of the methodology which includes an explanation of social process as well as discussion of the theory which will guide the analysis of data. The next section provides a thematic account of early career support before a discussion of the implications of the primary and secondary evidence presented along with the conceptual model.

\section{Literature Review}

In discussing the nature of academic work, there is a significant body of literature which deals with the issue as a technical process with an emphasis on the activities carried out. Bath and Smith (2004), for example, classify academic work as a combination of 'research, teaching or service' (p.10) and offer examples such as 'learning about new developments in one's discipline ... advising/mentoring/assisting colleagues ... teaching ... conducting research ... committee work' (p.11). Clegg (2008) examines the 
nature of academic work through the lens of academic identities and suggests that simple descriptions of academic activities are less useful than explanations which focus on, for example, the cultures and patterns of convention in which they take place. This raises the issue of academic work as a social process where what matters are the motivations, expectations, attitudes, beliefs and values of the actors and how they are influenced and shaped by other actors they come into contact with. On these issues, there is a significant body of evidence which suggests that the primary motivations for joining the profession are focused on 'intellectual challenges and stimulation' (Schenkein, 2001, p.836), a point reinforced by Gappa et al (2005) who suggest that one of the attractions of an academic career is that it allows people to 'engage in meaningful work' (p.36) within the context of 'core values long associated with faculty work' (Austin, 2002, p.106).

This social process perspective is important because it considers the relationship between the individual and the environment in which, in this case, they work. For example, in a study of junior faculty in the USA, Olsen and Crawford (1998) suggested that the 'person-organisation fit' (p.40) is crucial because 'fulfilment of work expectations affects employee job satisfaction, work commitment and other job related attitudes which in turn affect job performance and, ultimately, turnover' (p.39). In examining how new academics define and develop their own identities, Archer (2008a) suggests that it may have been affected by significant changes in the 'nature, organisation and purpose' (p.265) of higher education brought about by its massification, changes in job roles and specifications and the introduction of more regimes of performance measurement. Becher and Trowler (2001) develop this point further and question whether it is possible to 'hold onto values and practices from the past' (p.16) in a sector which has been subjected to change brought about by globalisation, massification and managerialism. Is there, for example, a mismatch between the social process of academic work and the environment in which it takes place?

Asmar (2002) suggests that there is a challenge in finding congruence between 'academic cultures that have traditionally lauded and rewarded disciplinary research' and the realities of a much more 
dynamic sector. The extent to which this has occurred has been and remains open to debate. On one hand, Clegg (2008) argues that 'traditional academic identities based on collegiality and the exercise of autonomy ... are indeed under threat' (p.331) whereas Becher and Trowler (2001) are much more equivocal and have identified a number of different ways in which academics have responded to these changes which vary from resistance at one end of the spectrum through to the enthusiastic adoption of new practices at the other. Archer (2008a) identifies the core values of academia as intellectual endeavour, criticality and professionalism' (p.270) and in examining the extent to which new academics share them with more experienced colleagues, finds reasons for both optimism and pessimism: New academics construct their identities around the same values as in the past but will the pressures and tensions of modern academic work allow them to live out these identities?

For the purposes of this paper, we would argue that modern academic work is characterised by three different tensions that academics new to the profession must navigate their way through. The first of these tensions is between the discipline of the academic and the department or institution in which they work. The root of this, Brew (2003) argues, is the tension between a 'disciplinary research culture' and a 'departmental learning milieu' (p.11) in which the new academic finds him or herself. Green (2009) offers a similar perspective and suggests that academic work should be viewed as being primarily located within a discipline; He suggests that, whilst academics may be comfortable within their own discipline, they are 'novices' in terms of contextualising that into higher education generally (p.35). According to Kember (1997), 'many university academics hardly consider themselves 'teachers' at all, instead visualising themselves more as members of a discipline' (p.255).

One of the arenas in which this tension is most frequently manifested is that of professional development and Hubball and Poole (2003) advocate 'structured programmes of study' (p.11) as the central point for new academics' professional development and these often take the form of postgraduate qualifications in academic practice. Comber and Walsh's (2008) work identified the disciplinary nature of these programmes as a central issue for discussion and argue that whilst they can be important in breaking 
down disciplinary barriers, they are often perceived within disciplines as an example of external intrusion. Bamber (2008), for example, identified previous studies which draw attention to the importance of 'practical skills' development (p.112) further indicating that discipline specific elements are important. Warhurst (2006) develops this point and proposes that successful programmes must involve elements of 'belonging, experience, doing and becoming' (p.114) implying that the content must be academically holistic. Wareing (2009) examined whether different disciplines have their own pedagogy and concluded that there is little evidence which suggests that they do. Perceptions are, however, important in this context because, where differences are perceived, 'it makes planning and conducting interdisciplinary and transdisciplinary activity in universities much more difficult' (p.925).

The second tension for new academics to negotiate is that of the competing demands placed on their time and resources. For Honan and Teferra (2001) the root cause of this is the difference between traditional conceptions of academic work and the reality of academic work. Adams (2002) develops this point by contrasting the expectations of new staff and the expectations of their host institutions: Whilst staff may view research as the core of their work, institutions have a view of academic work which also involves teaching and the wider aspects of academic life (p.5) with the result that new staff are often 'overwhelmed' by the variety of demands placed on them leaving 'little time to establish their research programmes' (p.7). In dealing with these tensions, Boyle and Boice (1998) argue that the formal and informal relationships between experienced and inexperienced staff in an academic department are crucial. Mentoring, for example, is a widely used support mechanism which can address many of these expectations issues. Austin (2002) suggests that across a number of studies, 'the helpfulness of departmental faculty' (p.104) was central and Boyle and Boice (1998) argue that the benefits of mentoring include 'improvements in risk taking, political savvy and specialised professional skills ... greater research productivity and career advancement' (p.158).

The final tension is, broadly speaking, between the visible and invisible rules which operate in academia and include, for example, those which are tacit and explicit, written and unwritten. For Trowler 
and Bamber (2005) these issues are crucial as the relationship between institutions and academics is one of 'multiple games with competing goals and different rules' (p.79). Austin (2002) suggests that this frequently manifests itself with institutional 'mixed messages' (p. 108), particularly around the relationship between teaching and research. Elen et al (2007) argue that a combination of pressure to publish in high quality journals and increasing demands for accountability inevitably lead teaching and research to 'become separate systems within the context of one organisation, the university' (p.125) whereby they are treated as fundamentally separate rather than as activities which are 'related through the common activity of scholarship' (Brew, 1999, p.297). The outcome for many new academics may be that teaching takes up a great deal of time but it is research profile which is most important for career progression. Trowler and Knight (2000) suggest that this is part of a cultural and behavioural problem within higher education institutions whereby the tacit is more important than explicit rules. Archer (2008b) summarises many of these issues by suggesting that 'becoming an academic is not smooth, straightforward, linear or automatic, but can also involve conflict and instances of inauthenticity, marginalisation and exclusion' (p.387). The paper now turns to discuss the gathering of primary data which examines how early career academics negotiate and navigate their way through these tensions.

\section{Methodology and Data Collection}

The starting point for the collection and analysis of primary data is the assumption that support for early career academics is best understood as a social rather than a technical or managerial process and, in developing this view, we follow Eden's (1992) description of social processes as those which involve the 'interaction and engagement between people' (p.799). In supporting this approach, Parry (1998), for example, suggests that social process analysis is useful in developing an understanding of the 'values, beliefs, attitudes and motivations' which determine the behaviours of people and Sampson et al (2002) argue that social processes are crucial in understanding the well-being of individuals in any collective group. The aim of the primary research, therefore, is to identify a series of themes through the accounts 
provided of the direct and indirect actors in the career support process in order to illustrate and understand the flow of related events (Saunders et al, 2009, p.497).

Ontologically, the social process analysis which follows is built on phenomenological foundations whereby what matters is the 'socially constructed' world of the participants in the research (Adcroft and Willis, 2008, p.314) and how they attach 'meaning to the described phenomenon' of career support (Folkestad, 2008, p.9). This underpinning suggests that individuals will often take a bundle of preconceptions into any given set of circumstances, what Macdonald et al (2006) describe as 'mythologies', and it is these rather than, say, any technical or managerial framework which governs attitudes and behaviours. The logical and natural outcome of this is that different actors in the process will hold different mythologies and, therefore, offer very different interpretations. In capturing the narratives of how career support experiences are interpreted by those involved, the data collection strategy was based around semi-structured interviews as this is the approach most likely to 'reveal regular interpretation practices' whereby different versions of 'actions, cognitive processes and other phenomena' (Talja, 1999, p.459) will be constructed.

The interviewees for this study are drawn from two research intensive university business and management schools in the UK. These schools were chosen on the basis that they are both taking part in a Higher Education Academy (HEA) funded project on the personal and discipline-specific development needs of NCAs in the areas covered by the Business, Management, Accounting and Finance (BMAF) subject centre. The ethical requirements of the two universities in which the schools are located for anonymity of both institutions and individuals means that neither can be identified in or by the presentation of data. The two schools share a number of similarities in terms of programmes delivered, size and composition of student cohorts, research-teaching orientation and academic staff profile. Thus both offer a range of programmes from undergraduate and taught postgraduate programmes in business, management and related fields through to professional and academic doctoral programmes. On these programmes, each school has around 1,100 undergraduate students and 550-650 taught postgraduate 
students. The profile of staff, in terms of experience and grade, is similar with a roughly equal proportion of staff at professor, reader, senior lecturer, lecturer and tutor/teaching fellow grades. Both schools are managed through a subject based divisional structure.

Both the general literature and the specific school practices in this study suggest that there are three main actors in the process of early career support; the NCAs themselves, senior staff who determine strategy and policy towards the recruitment and development of new academics and the central university provision of support. On this basis, all interviewees for this study came from one of these groups. In both schools, six academics who were within the first four years of their first academic appointment in a business or management school discipline were interviewed. All of these early career academics entered the profession through either an academic route (usually via a $\mathrm{PhD}$ programme) or a practitioner route from either industry or the public sector. In addition, five senior managers in each school were interviewed and these included Deans (or equivalent), Associate Deans for Teaching and Learning (or equivalent), Heads of Division (or equivalent) and human resource managers. Finally, one member of staff with responsibility for the PPAP in each university was interviewed. In each case, interviews were of 45-60 minutes duration and took place over two consecutive days. Interviews were recorded for reference purposes only (as required by the ethical regulations of each university) and detailed notes were taken. The main themes of enquiry used in the interviews with each group are presented in Appendix 1.

The analysis of the interview data is guided by what Braun and Clarke (2006) broadly define as 'thematic analysis' whereby the intention is to identify any common themes in early career support raised by the participants in the interviews. The main benefit of using this type of approach is that it offers an 'accessible and theoretically flexible approach to analysing qualitative data' (Braun and Clarke, 2006, p.77) which can be tailored to the needs of the specific research project. For this paper, we have identified two specific aims of the data analysis; first that key themes are identified and, second, that the interactions between these themes are explored as these are likely to be always important within any social process perspective. Thus, for each interview, we assume that the data collected reflects the 'interviewees' reality 
outside the interview' (Rapley, 2001, p.304) and that these realities will have elements that are both similar and different to other participants in the study, what Macdonald et al (2006) refer to as dissonance. In identifying the themes, we broadly follow Folkestad's (2008) and Braun and Clarke's (2006) approaches which begin with getting a sense of the whole followed by identifying, naming, interrogating and illustrating themes before finding ways to tie these essential elements together in a coherent manner.

\section{Findings}

In presenting the findings of the interviews, what becomes clear is that the broad framework in which career support happens is similar in the two schools although there are also some important differences. For example, NCAs in both schools are required to undertake a period of probation although that period differed between schools. Similarly, there is a compulsory PPAP in both schools which differ in length and content. Across the 24 interviews in the two schools, four themes have emerged as being significant in the support given to and required by NCAs; the management of expectations, career management, mentoring and professional development. Whilst these four themes are important in and of themselves, what also came across clearly from the interview data was that support tended to be most effective where NCAs created a blend of these themes most suited to their own requirements. In the presentation of findings, quotations from interviewees are presented as being from either NCAs or Senior Managers (SM) who come from both the school and the central university provider of the PPAP. The four themes which emerged from the interviews are presented below.

\section{Expectations}

"Our ambition is to be a world class business school and to do that we need to recruit the right staff. The world in which we operate means that we cannot be a top business school just by research and so that will determine how and what staff we recruit" SM5A 
"At my interview they really only asked me about my research so when I started and saw that teaching was just as important I felt like I had been thrown in at the deep end. Still, I worked through it with my mentors, and some other people, and now I know what I need to do" NCA1A

Across both schools there are similarities in where gaps in expectations appear and how these gaps are dealt with and managed. Across both schools, the two most significant areas where expectations were an issue were in the multi-dimensional nature of academic work and the culture in which staff are expected to build and manage their careers. Senior managers in both schools stressed the importance, for example, of staff building a balanced portfolio of teaching and research excellence and this importance was reflected in a series of mechanisms for career support which began with recruitment policies and feed into areas such as induction programmes, the PPAP and objective setting. Thus both schools had a multi-faceted approach to setting and managing the expectations of new staff, approaches in which NCAs were central and participative although this is not to suggest that there was not a degree of dissonance between the perspectives of senior managers and NCAs.

The interviewees suggested that this dissonance was the result of two factors. First, a number of NCAs pointed out that there was a contrast between institutional demands to meet targets and the need for staff to take responsibility for their own career management and development. The second cause was staff working in an academic culture for the first time. This was particularly acute for NCAs who had entered the profession from a non-academic practitioner background and also for those NCAs who were making the transition from being a $\mathrm{PhD}$ research student to a full time academic. In dealing with these gaps in expectations, senior management's perspective tended to be that their role was to provide a series of development and support opportunities for NCAs to take advantage of and that it was up to NCAs to find their own way of taking advantage of these opportunities. Where the dissonance had been most effectively managed was where NCAs were able to adapt the framework of opportunities to their own specific needs.

\section{Career Management}


"I would love to be able to give all staff, not just new staff, more time for research but we are stuck with big student numbers. Creating more discretionary time for people is very difficult" SM6A

"I found that, at first, teaching the large numbers took up all my time and doing any research was impossible. But there is still an unwritten rule that research matters. Teaching takes up most of your time but research is what gets you noticed and promoted" NCA3A

In managing careers, the main challenge raised by all the NCAs interviewed was that of finding a balance between teaching and research. There were two specific problems identified in this area. The first problem was in the relationship between explicit and implicit priorities. For example, senior managers in both schools explicitly stated that both teaching and research are crucial to career development yet at the same time many NCAs felt that there was a more implicit message that research was much more important as a career building activity. The second problem was one of resource constraints; within their respective universities, the two schools in the study are expected to recruit large numbers of students which many NCAs felt served to inflate their nominal teaching loads as they were preparing for classes and marking for the first time.

In managing the relationship between teaching and research, different NCAs dealt with it in different ways although nearly all pointed out that it was something that took them a while to work out and that often getting advice from more senior colleagues was crucial to the way in which they navigated the tensions. The most commonly held view was that the opportunity and encouragement to develop a research profile was a key factor in NCAs joining the schools and one of the most attractive elements of this was the individual nature of the research; NCAs were free to develop research in whatever ways they wished providing it contributed to them meeting both their own and the school's objectives. In this context, it was broadly accepted by both NCAs and senior managers that teaching would probably be a barrier to this in the early stages of career development and would remain so until NCAs were in a position to manage their careers and workloads in a more autonomous manner.

\section{Mentoring}


“At times, being an academic wasn't what I expected - trying to do research at the same time as teaching for the first time was a bit of a nightmare. But I got through it. What I found was that getting advice from senior people is invaluable" NCA3A

Both senior managers and NCAs across the two schools placed great importance on the different mentoring schemes in place to deal not only with the issues of expectations and career management mentioned already but in career support in general. In both schools, the mentoring schemes were clearly linked to the probation scheme that all NCAs are required to participate in; mentors have a significant role in, for example, setting objectives and developing ways in which these objectives are achieved. One difference in approach across the two schools centres on the degree of specialism of the mentor assigned to a new academic. In one of the schools, NCAs are assigned two mentors, one for teaching and one for research and in the other academics are assigned a Senior Colleague who has responsibilities to offer guidance and support across all academic activities. The main similarity, however, between the two schools was in the importance attached to both formal and informal mentoring as NCAs frequently identified collegiality as a crucial element in different types of support gained early in their careers.

\section{Professional Development}

"It is programme to teach learners, ie previous PhD students or practitioners, how to teach. I'd never taught before and I thought it was invaluable" NCA2B

"If academics need support in the university, they can find it. I've just finished my probation and feel that there were loads of opportunities for me to develop as an academic whilst I was doing it" NCA4A

The formal starting point for professional development in both schools is the centrally provided PPAP. There were both similarities and difference across the two schools. In both schools, for example, completion of the programme is compulsory as either an integral part of a probation system or as a contractual requirement. There were differences in scope and focus. In one school, new academics are required to undertake a two year programme consisting of taught elements and a reflective portfolio of work. In terms of scope, this goes beyond teaching and covers areas such as research supervision and 
pastoral support. In contrast, the other school offers a shorter and more focused programme which concentrates on teaching issues for new academic staff. Whilst the approaches taken are different, there are similarities in the attitude of staff to this mechanism for staff development. There was a general consensus, for example, about the benefits which accrue to staff who have no real teaching experiences prior to taking up their appointment who viewed the PPAP as an ideal introduction to teaching especially in light of the issues related to large groups, teaching for the first time and the tension between teaching and research. There were also similar criticisms of the two programmes across the two schools. The first of these criticisms focused on the requirement for all new staff to undertake these programmes, even those who had teaching experience already where it was seen as an unnecessary burden for staff who wanted to focus on developing a research profile. The final common issue across the two schools regarding these programmes was the balance between general and discipline specific content. Essentially, both programmes are general programmes and it is up to the individual participant to tailor their experience to their own disciplinary needs, usually on the basis of their own career ambitions and advice given from others in the school.

These qualifications are clearly important mechanisms for staff development but both NCAs and senior managers in both schools also stressed the importance of them as a starting point for continuous professional development (CPD) rather than an end point or self contained dimension. The way in which this has been developed across the two schools is a reflection of the view that staff must take responsibility for their own development and the school or university's role is simply to provide opportunities for this. It may also be influenced by the informal and collegial dimensions to staff development which predominate subsequently and this can simply be about being in the right place at the right time.

Whilst these themes are common across all the interviewees, it is important not to lose sight of the fact that each of the early career academics had a unique experience of career support. These unique experiences can be understood through how the different themes interact; across each new academic the relationship between, and the intensity of, these themes was different even though they may have been working from and within a common framework. For example, the starting point for career support was the 
setting of objectives for the probationary period as an institutional requirement. Whilst there was an element of diversity across the NCAs when we consider how those objectives were both set and met, what was common was that they were developed through discussion with senior colleagues and mentors. For some NCAs, the setting of objectives represented the first steps in dealing with gaps in expectations whereas for others is was the point at which these gaps became obvious, for the first time in some cases. For both of these groups, career management became the main mechanism through which issues were dealt with although support for career management was accessed in different ways. For example, a number of NCAs in both schools looked first to formal professional development mechanisms to establish some principles on which they could build and only later did these NCAs look to mentors and senior colleagues for support in dealing with more nuanced and locational elements of career management. Other NCAs used senior colleagues and mentors as the starting point for support and guidance in dealing with tensions and gaps in expectations and then tailored their professional development around the advice they had been given. For all NCAs, both mentoring and professional development were important but they were important for different reasons and, frequently, at different times.

For most of the NCAs interviewed in the study, this issue of integration was best seen through the lens of social process rather than as a managerial or technical process. For one NCA, for example, the crucial element of integration and social process was being able to distinguish between the "written and unwritten rules" (NCA1B). For this NCA, the formal terms and conditions of academic life, as laid out in the objectives set at the start of the probation period, only became meaningful and useful when they were interpreted by their senior colleague which allowed for the prioritisation of teaching and research work according to the behavioural norms and expectations of the school. This was common across many of the NCAs; senior colleagues and mentors were not seen simply as resources to provide technical advice on, for example, teaching large classes or submitting to high ranked journals, but rather as people who offered realistic interpretations of the school's priorities. NCA1B commented: "I was lucky with my senior colleague as she helped me read between the lines, to be honest she did most of the reading for me ... the 
school didn't say it but some objectives were always more important than others and when she helped me work that out, things became much easier ... once I knew what was really important, I knew what help I needed and where I could go and get it from ... not everyone was as lucky as me in having a good senior colleague as got on really well and that is what got me through probation more than anything else".

\section{Discussion and Conclusions}

Whilst the twelve NCAs interviewed for this paper offered separate and very different accounts of their experiences, the common framework in which they were supported makes it possible to summarise the data into key emerging themes. The most significant of these themes is expectations and the gap between preconceptions of academic careers and the reality of academic careers. Albeit to varying degrees, all twelve NCAs interviewed shared this experience and, for most, the managing of this expectations gap provided the starting point and impetus for career support. In this context, there are three elements of support which emerged. First, the importance of career management and resolving issues, both long and short term, in the relationship between teaching and research (and other elements of academic work). Like Elen et al (2007) and Brew (2003), this study suggests that the main tension for new academics is in the relationship between teaching (which takes up a great deal of time) and research (which is essential for career progression in universities like the ones in this study).

The second key element of support emerging from the study is that of mentoring which was universally viewed as a positive intervention both by senior managers (who were likely to act as mentors) and NCAs (who were mentored). This element, however, went wider than just the formal senior colleague schemes and included many informal relationships formed between NCAs and colleagues who were the primary sources of support and advice. As Boyle and Boice (1998) suggested, and this study confirms, much career support is grounded in the relationships between experienced and less experienced academics. The final element of support identified in this study is that of professional development which emphasised the role of PPAPs. The experiences of the NCAs in this study are, again, typical of the studies in other areas (see, for example, Hubball and Poole, 2003, Bamber, 2008 and Wareing, 2009) which suggests that 
successful programmes are built on a balance between discipline specific and more generic content and the ability of NCAs to tailor the programme to their own needs.

The consistency between the findings of this and previous studies suggest a degree of reliability but in developing the literature further, we would suggest that career support for new academics is not just about the content of these dimensions viewed in isolation, but rather that its effectiveness is significantly determined by how these link together: NCAs are recruited into research led schools with high expectations of research activity to contribute to the fulfilment of the mission to achieve global excellence. This implicitly has high expectations of both teaching performance and research outputs. This creates problems of workload management and career progression which are addressed through a variety of different mechanisms including PPAPs, the provision of senior colleague mentors, formal and informal relationships which help staff develop strategies to manage workloads and the teaching-research relationship and a suite of CPD opportunities which staff can access as and when they feel it appropriate for their individual career development. It would appear that there is a symbiotic relationship between the four elements and that any effective approach should recognise this rather than searching for a single intervention to address the issues. Figure 1 presents this argument in diagrammatic form and suggests that any distinction between expectations, career management, mentoring and professional development is artificial and counterproductive as they merge into each other. 


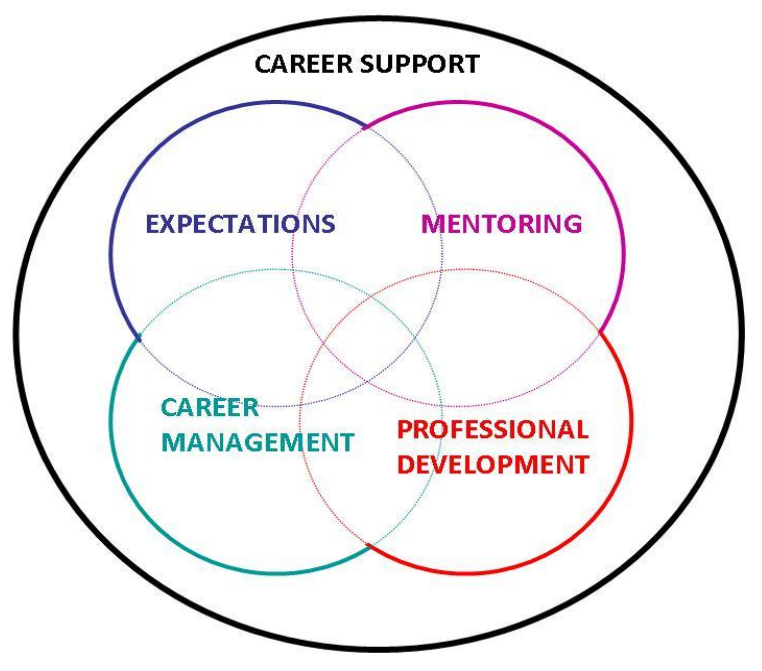

If the first key conclusion of the paper is, therefore, that it is the relationship between support mechanisms which matters most, the second key conclusion is that this holistic view of career support is best understood as a social process rather than a technical or managerial process. Where NCAs, for example, had difficulties it tended to be because of gaps in expected relationships be they in the form of expectations of academic careers, the tensions between teaching and research, the difficulties of reconciling institutional demands and individual aspirations or between the written and unwritten rules which govern and influence academic life. Where NCAs were successful in dealing with these different types of dissonance was, in the main, where strong social processes were in place, especially those relationships between the NCA and senior and other colleagues. In these two schools at least, the success or otherwise of the professional and personal support offered to NCAs was primarily determined by the human relationships involved. 


\section{Acknowledgements}

The authors would like to thank the Business, Management, Accounting and Finance subject centre (BMAF) of the Higher Education Academy (HEA) who funded the research on which this paper is based.

\section{References}

Adams, K. A. (2002) What Colleges and Universities Want in New Faculty, Association of American Colleges and Universities, Washington, USA.

Adcroft, A. \& Willis, R. (2008) A snapshot of strategy research 2002-2006, Journal of Management History, 14(4), 313-333.

Archer, L. (2008a) The new neoliberal subjects? Young/er academics' constructions of professional identity, Journal of Education Policy, 23(3), 265-285.

Archer, L. (2008b) Younger academics' constructions of "authenticity", "success" and professional identity, Studies in Higher Education, 33(4), 385-403.

Asmar, C. (2002) Strategies to enhance learning and teaching in a research-extensive university, The International Journal for Academic Development, 7(1), 18-29.

Austin, A. E. (2002) Preparing the next generation of faculty, The Journal of Higher Education, 73(1), 94-122.

Bamber, V. (2008) Evaluating lecturer development programmes: received wisdom or selfknowledge, International Journal for Academic Development, 13(2), 107-116.

Bath, D. \& Smith, C. (2004) Academic Developers: An academic tribe claiming their territory in higher education, International Journal for Academic Development, 9(1), 9-27.

Becher, T. \& Trowler, P.R. (2001) Academic Tribes and Territories: Intellectual enquiry and the culture of disciplines, The Society for Research into Higher Education and Open University Press, Buckingham, UK.

Boyle, P. \& Boice, B. (1998) Systematic Mentoring for New Faculty Teachers and Graduate Teaching Assistants, Innovative Higher Education, 22(3), 157-179.

Braun, V. and Clarke, V. (2006) Using thematic analysis in psychology, Qualitative Research in Psychology, 3(2), 77-101.

Brew, A. (1999) Research and Teaching: changing relationships in a changing context, Studies in Higher Education, 24(3), 291-301.

Brew, A. (2003) Teaching and Research: New relationships and their implications for inquirybased teaching and learning in higher education, Higher Education Research and Development, 22(1), 318. 329-345.

Clegg, S. (2008) Academic identities under threat, British Education Research Journal, 34(3),

Comber, D. \& Walsh, L. (2008) Enhancing educational development for new academic staff through the inclusion and comparison of disciplinary pedagogies, Final Report, Scottish Higher Education Enhancement Research, Higher Education Academy, York, UK.

Eden, C. (1992) Strategy development as a social process, Journal of Management Studies, 29(6), 799-811.

Elen, J., Lindblom-Ylanne, S. \& Clement, M. (2007) Faculty Development in Research-Intensive Universities: The role of academics' conceptions of the relationship between research and teaching, International Journal for Academic Development, 12(2), 123-139.

Folkestad, B. (2008) Analysing Interview Data: Possibilities and Challenges, Eurosphere Working Paper Series No. 13. 
Gappa, J. M., Austin, A. E. \& Trice, A. G. (2005) Rethinking academic work and workplaces, Change, November-December, 32-39.

Green, D. A. (2009) New academics' perceptions of the language of teaching and learning: identifying and overcoming linguistic barriers, International Journal for Academic Development, 14(1), $33-45$.

Honan, J.P. \& Teferra, D. (2001) The US academic profession: Key policy challenges, Higher Education, 41, 183-203.

Hubball, H. \& Poole, G. (2003) A Learning-centred Faculty Certificate Programme on University Teaching, International Journal for Academic Development, 8(1/2), 11-24.

Kember, D. (1997) A reconceptualisation of the research into university academics' conceptions of teaching, Learning and Instruction, 7(3), 255-275.

Macdonald, I., Burke, C. \& Stewart, K. (2006) Systems Leadership: Creating positive organisations, Gower Publishing Ltd, Surrey, UK.

Olsen, D. \& Crawford, E. A. (1998) A five year study of junior faculty expectations about their work, The Review of Higher Education, 22(1), 39-54.

Parry, K.W. (1998) Grounded Theory and Social Process: A new direction for leadership research, Leadership Quarterly, 9(1), 85-105.

Rapley, T. J. (2001) The art(fullness) of open ended interviews: some considerations on analysing interviews, Qualitative Research, 1(3), 303-323.

Sampson, R., Morenoff, J.D. \& Gannon-Rowley, T. (2002) Assessing 'neighbourhood effects': Social processes and new directions in research, Annual Review of Sociology, 28, 443-478.

Saunders, M., Lewis, P. \& Thornhill, A. (2009) Research Methods for Business Students (5 ${ }^{\text {th }}$ Edition), Prentice Hall, UK.

Schenkein, H. A. (2001) Factors considered by new faculty in their decision to choose careers in academic dentistry, Journal of Dental Education, 65(1), 832-840.

Talja, S. (1999) Analysing Qualitative Interview Data: The discourse analytic method, Library and Information Science Research, 21(4), 459-477.

Trowler, P. \& Knight, P. T. (2000) Coming to Know in Higher Education: theorising faculty entry to new work contexts, Higher Education Research and Development, 19(1), 27-42

Trowler, P. \& Bamber, R. (2005) Compulsory Higher Education Teacher Training: Joined up policies, institutional architectures and enhancement cultures, International Journal for Academic Development, 10(2), 79-93.

Wareing, S. (2009) Disciplines, discourse and Orientalism: The implications for postgraduate certificates in learning and teaching in higher education, Studies in Higher Education, 34(8), 917-928.

Warhurst, R.P. (2006) "We really felt part of something": Participatory learning among peers within a university teaching-development community of practice, International Journal for Academic Development, 11(2), 111-122. 
Appendix 1: Questions in Interview Protocol

\begin{tabular}{|c|c|c|}
\hline Senior Staff & Institutional Lead for PG Qualification & New Academic Staff \\
\hline $\begin{array}{l}\text { Tell me about the sort of } \\
\text { work that new lecturers } \\
\text { undertake in your } \\
\text { department? } \\
\text { What sort of information is } \\
\text { routinely available to new } \\
\text { lecturers and who would } \\
\text { make sure that they } \\
\text { received the information? } \\
\text { What contact have you had } \\
\text { with your new lecturing } \\
\text { staff? benefits/particular } \\
\text { What boutice } \\
\text { contributions do you notice } \\
\text { arise from the employment } \\
\text { of new lecturers? } \\
\text { What challenges and } \\
\text { difficulties have you } \\
\text { experienced relating to the } \\
\text { employment of new } \\
\text { lecturers? } \\
\text { Please describe the } \\
\text { formal/mandatory support } \\
\text { offered to new lecturers } \\
\text { What about } \\
\text { informal/voluntary/self- } \\
\text { selected support - what } \\
\text { might this include and what } \\
\text { role does this play in } \\
\text { supporting new lecturers? } \\
\text { To what extent are new } \\
\text { lecturing staff involved in } \\
\text { regular review and } \\
\text { feedback processes } \\
\text { Are there any other points } \\
\text { relating to new lecturers } \\
\text { that you would like to } \\
\text { make that we have not } \\
\text { covered in this interview? }\end{array}$ & 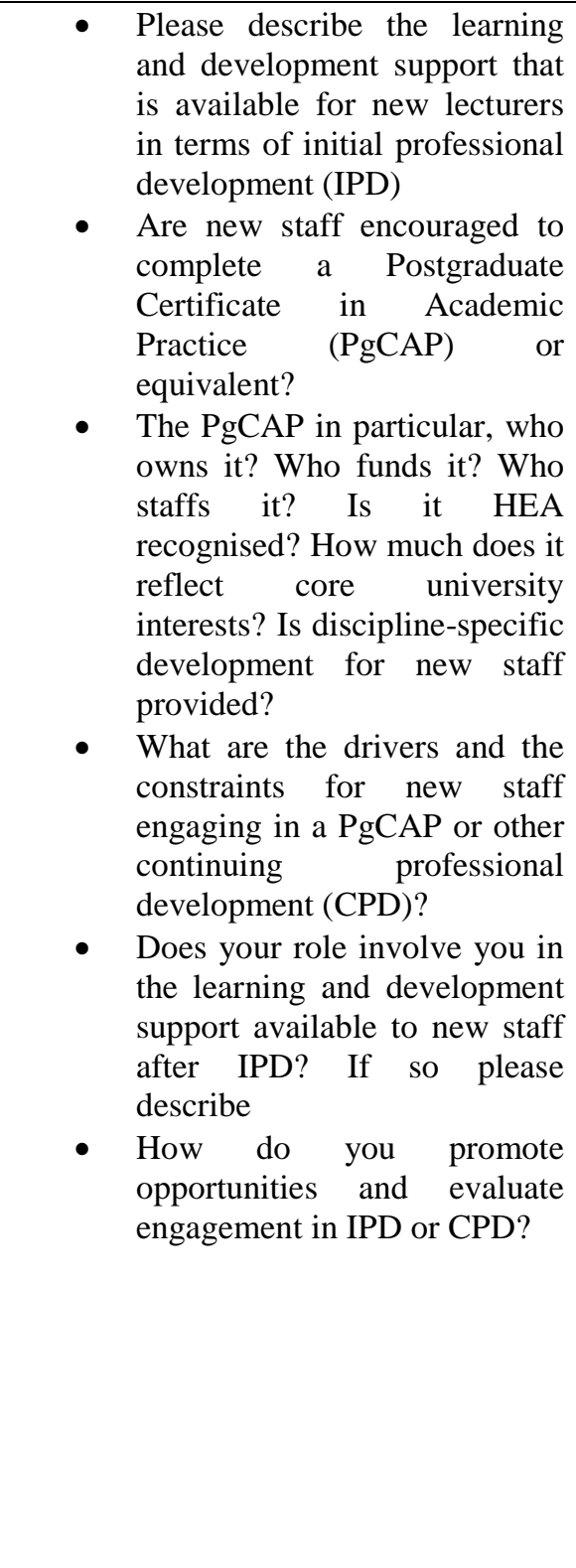 & $\begin{array}{l}\text { - Tell me about the sort of work } \\
\text { that you undertake in your } \\
\text { department? } \\
\text { Do you have the same access to } \\
\text { facilities as other academic } \\
\text { staff? } \\
\text { - What sort of information is } \\
\text { routinely available to new } \\
\text { lecturers and who would make } \\
\text { sure that they received the } \\
\text { information? } \\
\text { What contact have you had with } \\
\text { your line manager and your } \\
\text { mentor? } \\
\text { What are the three things that } \\
\text { you feel were most useful to you } \\
\text { on first joining this Institution? } \\
\text { What three things did you find } \\
\text { most frustrating? } \\
\text { What induction did you } \\
\text { - } \text { - Wndertake when you joined this } \\
\text { University? } \\
\text { Do you feel that you need on- } \\
\text { going support as a new lecturer? } \\
\text { What ongoing support were you } \\
\text { offered? } \\
\text { Were you allocated (or did you } \\
\text { choose) a mentor (or equivalent } \\
\text { are yourt person)? } \\
\text { undertake and/or are any of the } \\
\text { programmes/courses mandatory? }\end{array}$ \\
\hline
\end{tabular}

